\title{
Electrical Performance Evaluations for a Dielectric Barrier Discharge Plasma Actuator
}

\author{
Andrew R. H. Rigit, Lai Koon Chun and David Bong Boon Liang \\ Faculty of Engineering \\ Universiti Malaysia Sarawak \\ 94300 Kota Samarahan, Sarawak, Malaysia
}

\begin{abstract}
Dielectric barrier discharge (DBD) plasma actuator requires an operating voltage of several kilovolts. However, during the experiment, charge accumulated on the surface of the DBD plasma actuator can reduce the electric field at the location of a microdischarge and result in current termination. This study aims to investigate the maximum voltage the actuators can withstand before the electrical breakdown happens, by varying a number of parameters include the gapping designs and dielectric thicknesses. Besides, the required threshold voltage before the microdischarges can be generated is also described in this study.
\end{abstract}

\section{INTRODUCTION}

Since decades, plasma science is a field of growing interest. Plasma, which defines the ionized state of gases, has become increasingly important for various industrial applications [1]. The device in-used, plasma actuator is named after its ability to establish the electric wind or ionic flow. There are two mostused actuators, namely corona discharge plasma actuator and dielectric barrier discharge (DBD) plasma actuator [2]. The latter design will be analysed in this study.

Dielectric barrier discharge (DBD), which also known as surface DBD (SDBD) has been widely used for the industrial applications and aerodynamic flow control [3,4]. It is a nonthermal discharge under atmospheric pressure that can generate UV emission and low-temperature plasma in the air. The discharge is performed at the surface of a dielectric layer between several electrodes mounted flush at both sides in an asymmetric configuration. The experimental layout and essential connections is shown in Fig. 1.

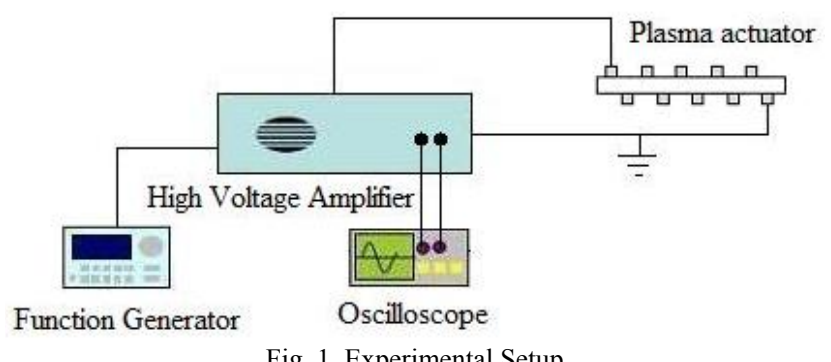

Fig. 1. Experimental Setup
The DBD proceeds in most gases or atmospheric air through a large number of separate current filaments referred to as microdischarges. Microdischarges have complex dynamic structure and are formed by channel streamers that repeatedly strike at the same place as the polarity of the applied voltage changes, appearing to the eye as bright filaments [5]. Charge accumulated on the surface of the dielectric barrier reduces the electric field at the location of a microdischarge, resulting in current termination within tens of nanoseconds after breakdown.

The plasma can be generated by exciting the anode of the plasma actuator with a high AC voltage while the cathode is grounded [6]. However, there exists a threshold voltage before the plasma can be produced from the plasma actuator [7]. This ignition voltage, or known as plasma on voltage (POV), for a plasma actuator varies accordingly to the dielectric thickness. It is mentioned that the required POV was $5.4 \mathrm{kV}$ for a $0.8-\mathrm{mm}$ thick PCB-based actuator [8]. Besides, reports of [9] revealed that the total plasma power of an actuator was equal to the power loss by dielectric heating before the initiation of the plasma. It was also mentioned that the POV for a quartz-based actuator was $2.5 \mathrm{kV}$ at a thickness of $1 \mathrm{~mm}$ [9]. In other words, one should supply a sufficient high voltage in order to produce a non-zero net plasma power to the plasma actuator. Thus, this study targets to investigate the electrical performances of the plasma actuator, in relation to the minimum required plasma ignition voltage (POV) and the maximum withstand voltage $\left(\mathrm{V}_{\text {MAX }}\right)$.

\section{EXPERIMENTAL APPARATUS}

In this study, the desired high voltage was supplied by a high voltage power amplifier (TREK Model 30/20A) driven by a function generator (GW INSTEK Model GFG-8020H). The digital function generator can supply the voltage $\mathrm{V}= \pm 0-10 \mathrm{~V}$ and provide frequency in a range from $0.2 \mathrm{~Hz}$ to $2 \mathrm{MHz}$. Besides, the high voltage power amplifier has a fixed gain of $3000 \mathrm{~V} / \mathrm{V}$ and is capable of providing precise control of output voltage $\mathrm{V}$ in the range from 0 to $\pm 30 \mathrm{kV}$ peak $\mathrm{AC}$ with an output current range of 0 to $\pm 20 \mathrm{~mA}$ peak AC. This amplifier was connected to the top actuator (as anode) of the plasma 